\title{
In vivo HAPLOID INDUCTION AND EFFICIENCY OF TWO CHROMOSOME DUPLICATION PROTOCOLS IN TROPICAL MAIZE
}

\author{
Indução in vivo de haploides e eficiência de dois protocolos de duplicação \\ cromossômica em milho tropical
}

\author{
Evellyn Giselly de Oliveira Couto ${ }^{1}$, Édila Vilela de Resende Von Pinho ${ }^{2}$, Renzo Garcia Von Pinho ${ }^{2}$, \\ Adriano Delly Veiga ${ }^{3}$, Fernanda de Oliveira Bustamante ${ }^{4}$, Kaio Olimpio das Graças Dias ${ }^{4}$
}

\begin{abstract}
Artificial chromosome duplication is one of the most important process in the attainment of doubled haploids in maize. This study aimed to evaluate the induction ability of the inducer line KEMS in a tropical climate and test the efficiency of the R1-Navajo marker by flow cytometry to evaluate two chromosome duplication protocols and analyze the development of the doubled haploids in the field. To accomplish this goal, four genotypes (F1 and F2 generations) were crossed with the haploid inducer line KEMS. The seeds obtained were selected using the R1-Navajo marker and subject to two chromosome duplication protocols. Duplication was confirmed using flow cytometry. The percentages of self-fertilized plants after duplication as well as the quantities of doubled haploid seeds obtained after the self-fertilization processes were analyzed. It was observed that the germplasm influences haploid induction but not the duplication rates of the tested protocols. Protocol 2 was more efficient for the duplication of haploids, in the percentage of self-fertilized plants after duplication, and in the attainment of doubled haploid lines. Moreover, the haploid inducer line KEMS can produce haploids in a tropical climate. Other markers, in addition to the R1-Navajo system, should be used in the selection of haploid seeds.
\end{abstract}

Index terms: R-Navajo; colchicine; induction of maternal haploids; Zea mays.

\section{RESUMO}

A duplicação cromossômica artificial está dentre as etapas mais importantes na obtenção de duplo-haploides em milho. Este estudo objetivou avaliar a capacidade de indução da linhagem indutora KEMS em clima tropical e testar a eficiência do marcador R1-navajo por meio de citometria de fluxo; avaliar dois protocolos de duplicação cromossômica e, analisar o desenvolvimento dos haploides duplicados no campo. Para isso, quatro genótipos (gerações F1 e F2) foram cruzados com a linhagem KEMS. As sementes obtidas foram selecionadas pelo marcador R1-navajo e submetidas a dois protocolos de duplicação cromossômica. A duplicação foi confirmada por meio de citometria de fluxo. As porcentagens de plantas autofecundadas após duplicação foram analisadas, bem como as quantidades de sementes duplo-haploides obtidas após as autofecundações. Foi observado que o germoplasma influencia a indução de haploides, mas não na taxa de duplicação dos protocolos testados. O protocolo 2 foi mais eficiente na duplicação de haploides, na porcentagem de plantas autofecundadas após duplicação, e na obtenção de linhagens duplo-haploides. Além disso, a linhagem indutora KEMS pode induzir haploides em clima tropical. Outros marcadores além do sistema do R1-navajo devem ser utilizados na seleção de sementes haploides.

Termos para indexação: R-navajo; colchicina; indução de haploides maternos; Zea mays.

\section{INTRODUCTION}

Doubled haploid technology has been used in breeding programs for several decades in various species (Li et al., 2013). Various private companies produce doubled haploid lines for the attainment of hybrid maize. However, information concerning the efficiency of the technique in public institutions is still scarce.
The implementation of the doubled haploid method in maize requires the use of haploid inducer lines. Generally, these haploid inducer lines have a temperate origin, which hampers the handling and development of these lines in tropical conditions. According to Rotarenco et al. (2010) and Dang et al. (2012), some haploid inducer lines have been developed and have relatively high haploid induction rates, such as: MHI with $7.2 \%$ induction, the modern European line RWS with $8 \%$ induction, and the

\footnotetext{
${ }^{1}$ Universidade Federal de Lavras/UFLA - Departamento de Biologia/ DBI - Cx. P. 3037-37200-000 - Lavras - MG - Brasil - evellyn.couto@yahoo.com.br 2Universidade Federal de Lavras/UFLA - Departamento de Agricultura/DAG - Lavras - MG - Brasil

${ }^{3}$ Empresa Brasileira de Pesquisa Agropecuária/EMBRAPA - Embrapa Cerrados - Planaltina - DF - Brasil

${ }^{4}$ Universidade Federal de Lavras/UFLA - Departamento de Biologia/DBI - Lavras - MG - Brasil

Received in april 1, 2015 and approved in july 27, 2015
} 
PHI line with $12.8 \%$ induction. However, some limiting factors exist in the haploid induction technique such as the haploid frequency may be influenced by the hybrid used as the donor (Kebede et al., 2011; Prigge et al., 2011).

Haploids obtained by inducer lines are selected using a morphologic marker based on the anthocyanin pigmentation in the seed endosperm. This pigmentation is controlled by the R1-Navajo gene (Chase; Nanda, 1965). This gene shows dominant allelic interactions. In addition, R1-Navajo expression can be reduced due to the female parent because it can carry known inhibitor genes (Melchinger et al. 2014). Other morphological markers have been used to select haploids such as plant height, plant vigor, and the absence of ligule (Prigge et al., 2012). Moreover, other techniques such as flow cytometry and molecular markers have also been used (Wu et al., 2014; Couto et al., 2015).

As one of the most important stages in the attainment of the doubled haploids, artificial chromosome duplication is noteworthy. Few methods of chromosome duplication have been tested and published (Eder; Chalik, 2002; Castillo et al., 2009; Häntzschel; Weber, 2010). Duplication protocols using antimitotics have been used increasingly, because they promote the chromosomic duplication/doubling and the attainment of double-haploid strains that are completely homozygous. Castillo et al. (2009) suggested that time, genotype, and concentration factors influence chromosome duplication when colchicine is used. However, information concerning the behavior and efficiency of chromosome duplication requires further research.

In that context, the objectives of this study were a) to evaluate the induction capacity of the haploid inducer line KEMS in a tropical climate and test the efficiency of the R1-Navajo morphological marker using flow cytometry and b) to evaluate two protocols of chromosome duplication and analyze the development of the duplicated haploids in the field.

\section{MATERIAL AND METHODS}

\section{Evaluated hybrids}

The haploid inducer line KEMS (Shatskaya et al., 1994) was used as a pollen donor and crossed with four simple hybrids (DKB393, GNS 3225, GNS 364, and GNS 3032) and their F2 generations. The cross field test occurred in Cravinhos, in the State of São Paulo (650 m altitude and $21^{\circ} 20^{\prime} 25^{\prime} \mathrm{S}, 47^{\circ} 43^{\prime} 46^{\prime} \mathrm{W}$ ), in the second season of 2011. The culture treatments were conducted according to recommendations for maize culture.

\section{Identification of haploids using the R-Navajo marker}

To obtain probable haploids, the seeds obtained with the previously cited crosses were visually separated according to the purple color of the endosperm and the white color of the embryo due to the R1-Navajo marker (Chase; Nanda, 1965). The seeds of the probable haploids were further divided and subjected to two different chromosome duplication protocols. The total quantity of the seeds selected as haploids according to the R1Navajo marker was used in the statistical analyses for the calculation of the haploid induction rate (HIR) of the KEMS line.

\section{Artificial chromosome duplication}

Two chromosome duplication protocols were used. For Protocol 1, maize seedlings (five days after germination) were subjected to treatment with a $0.04 \%$ colchicine solution and $0.5 \%$ dimethyl sulfoxide (DMSO) for 12 hours and kept in the dark at $20^{\circ} \mathrm{C}$ (Prasanna et al., 2012). For Protocol 2, the selected seeds were sown in trays containing sand and vermiculite (ratio 1:1). After 10 days, the roots of the plants were washed in water, immersed in $0.1 \%$ colchicine solution, $0.1 \%$ DMSO, and $0.1 \%$ Tween 20 for six hours in the presence of light at ambient temperature (approximately $22{ }^{\circ} \mathrm{C}$ ) according to the method of Paul Newell (non-published data).

After the duplication process, the seedlings and roots subjected to the colchicine treatment, in the two protocols, were washed for 40 minutes with running water and transferred to a greenhouse where they were maintained for 20 days.

\section{Flow cytometry}

At fourteen days after chromosome duplication, leaf samples were collected and analyzed with a flow cytometer to identify duplicated plants and evaluate of the efficiency of the duplication protocols.

The estimate of the quantity of DNA was obtained from the leaf tissue of the parents and the descendants originating from that cross that survived chromosome duplication. For each sample, approximately 20-30 mg of young leaves of the evaluated individual were used. The Vicia faba species (DNA quantity $26.9 \mathrm{pg} / 2 \mathrm{C}$ ) was used as an external reference standard. The samples were ground in a Petri dish containing $1 \mathrm{~mL}$ of cool LB01 buffer, according to the method of Dolezel (1997), for the attainment of the nuclear suspension, to which $2.5 \mu \mathrm{L}$ of RNase was added, and the samples were stained with $25 \mu \mathrm{L}$ of propidium iodide $\left(1 \mathrm{mg} \mathrm{mL}^{-1}\right)$. For each sample, 
a minimum of 10,000 nuclei were analyzed. Histograms were obtained using a FacsCalibur (Becton Dickinson) cytometer with the Cell Quest (Becton, Dickinson and Company, San Jose, CA, USA) program and analyzed using the WinMDI 2.8 software (2009).

\section{Evaluations of self-fertilization and quantities of seeds obtained from duplicated plants}

After 20 days of post-chromosome-duplication acclimatization and after flow cytometry analysis, plants that underwent both protocols were transplanted to a protected environment at the HortiAgro company, located in the municipality of Ijaci, MG $(830 \mathrm{~m}$ altitude and $\left.21^{\circ} 9^{\prime} 24^{\prime} \mathrm{S}, 44^{\circ} 55^{\prime} 34^{\prime} \mathrm{W}\right)$. All plants that produced pollen and that had a synchronized style and stigma were selffertilized for the maintenance and multiplication of seeds.

Information about the self-fertilized plants was collected, and tracking of the ploidies was conducted via flow cytometry. Moreover, the quantity of seeds obtained after the self-fertilization processes and the quantity of the seeds of the doubled haploids were analyzed.

\section{Statistical analysis}

Statistical analyses were performed to evaluate the induction capacity of the haploid by R-Navajo and by flow cytometry, artificial chromosome duplication, and quantity of seeds obtained from duplicated plants, according to the method described by Basttistelli et al. (2013). All experiments were performed without replicates. The generation was used as the replication, and the ratios observed were evaluated using the generalized linear mixed model approach (GLMM) because overdispersion was detected (Nunes; Morais; Bueno Filho, 2004). In this case, the binomial GLMM was employed as a logit link according to the following description in which the protocol analysis is used as an example:

$$
\begin{aligned}
& \frac{R_{i j k}}{p_{i j k}} \sim \frac{\operatorname{Binomial}\left(m_{i j k}, \pi_{i j k}\right)}{m_{i}} \\
& \log \left(\frac{\pi_{i j k}}{1-\pi_{i j k}}\right)=\mu+p_{i}+h_{j}+g_{k}+p h_{i j}+p_{i j k}
\end{aligned}
$$

where $\mathrm{R}_{\mathrm{ijk}} / \mathrm{p}_{\mathrm{ijk}}$ is the ratio observed in the portion of plants that underwent protocol $\mathrm{i}$ for hybrid $\mathrm{j}$ in generation $\mathrm{k}$ admitted conditionally, independent of the random effect of the portion; $\mu$ is the intercept; $p_{i}$ is the fixed effect of protocol $i$; $h_{j}$ is the fixed effect of hybrid $j ; g_{k}$ is the fixed effect of generation $\mathrm{k}$; $\mathrm{ph}_{\mathrm{ij}}$ is the fixed effect of the interaction of hybrid $\mathrm{j}$ with protocol $\mathrm{i}$; and $\mathrm{p}_{\mathrm{ijk}}$ is the random effect of portion ijk, where pijk $\sim \mathrm{N}(0$,$) .$

The GLMM was adjusted with estimation of the fixed and random effects, as well as the variance components, via the restricted maximum likelihood (REML, Patterson and Thompson, 1971) using the lme4 pack of the R program (Bates; Maechler; Bolker, 2014).

The significance of the effects of the model was verified via deviance analysis with the application of the $\chi^{2}$ (cui-square) statistical test with a $5 \%$ probability. For the effects where significant differences were evident, a grouping was performed based on the Mahalanobis distance using the nearest neighbor method, and the cutoff point was established using the bootstrap resampling method.

\section{RESULTS AND DISCUSSION}

\section{Identification of haploids using the R1-Navajo marker}

The quantities of seeds obtained from the crosses among the inducer line KEMS and the simple hybrids GNS 3032, GNS 3225, GNS 364, and DKB 393 and their F2 generations are shown in Table 1. The probable haploids were selected from these seeds according to the R1-Navajo system marker (Chase; Nanda, 1965).

Using the deviance analysis, it can be observed

Table 1: Total of seeds obtained (T) and quantities of seeds classified as haploids selected by the R1-Navajo morphologic marker (Q) from different hybrids and generations of maize.

\begin{tabular}{cccc}
\hline Hybrids & Generations & T & Q \\
\hline \multirow{2}{*}{ GNS3225 } & F1 & 2236 & 126 \\
& F2 & 2284 & 145 \\
GNS3264 & F1 & 2523 & 241 \\
& F2 & 1450 & 135 \\
GNS3032 & F1 & 1193 & 177 \\
& F2 & 238 & 47 \\
DKB393 & F1 & 3486 & 130 \\
& F2 & 1904 & 85 \\
\hline
\end{tabular}

that the different hybrids influence the HIR when using the R1-navajo morphologic marker (Figure 1A). No significant differences were found in the HIR between the generations of hybrids used. These results 
corroborate those observed by Battistelli et al. (2013), who demonstrated that a generation of endogamy does not interfere with the HIR.

Differences between genotypes and the HIR in maize have been reported by several authors (Battistelli et al., 2013; Eder; Chalyk, 2002; Rober; Gordillo; Geiger, 2005). The average HIR of the selected haploids using the R1-Navajo marker was 8.5\%. Battistelli et al. (2013), using the same haploid inducer line, obtained an average induction rate of $7.1 \%$. Shatskaya et al. (1994) obtained values varying from $6.3 \%$ to $8 \%$. Differences between the hybrids for the HIR of maize haploids have previously been reported by other authors (Kebede et al., 2011; Wu et al., 2014). According to Belicuas et al. (2007), these rate differences occur due to the variable expressivity of the R1-Navajo gene, which does not produce precise indication of the seeds.

According to Rotarenco, Dicu and Sarmaniuc (2009), induction rates may depend on the method used in the crosses and the pollination period. Better results were obtained when the authors used manual pollination than when open pollination was used. However, Geiger and Gordillo (2009) cite that experienced breeders can obtain a higher HIR using non-controlled pollination processes. Moreover, according to Kebede et al. (2011), the environmental conditions interfere with the HIR.

\section{Haploid identification by flow cytometry}

Haploids were classified as those individuals who present a characteristic peak of ploidy of $x$ in the histograms, according to Battistelli et al. (2013), independent of whether the samples have undergone duplication. Using this analysis, it was possible to verify the efficiency of the R1-Navajo marker.

In the deviance analysis, a significant difference was found between the hybrids. In the grouping based on the Mahalanobis distance, however, the averages were the same, that is, at a probability of $5 \%$, the hybrids did not differ in the real haploid rate (Figure 1B).

Considering the HIR observed in this study, it is perceived that the actual percentage of haploid induction was lower than that obtained using the R1-Navajo marker. Thus, it is possible to verify that the R1-Navajo marker is inefficient and that other markers need to be used. Regarding the averages, an error rate of $33.5 \%$ was observed because the average of the haploids identified by the R1-Navajo marker was $8.50 \%$, whereas the average of the haploids identified by flow cytometry was $2.85 \%$ (Figures 1A and 1B).

As described by Belicuas et al. (2007), the R1navajo gene presents variable expressivity, and thus, the marker does not provide a precise indication of the seeds, which allows false haploids to be selected. To avoid this error, Prigge et al. (2011) recommended analyzing and separating the haploid seeds after the harvest because the drying stage generates a darker color of the embryo, contributing to erroneous selection. Moreover, other morphologic markers may be used in the detection of the false haploids, such as the color of the stem, ligule, and vertical leaves involving the stem (Prigge et al., 2012).
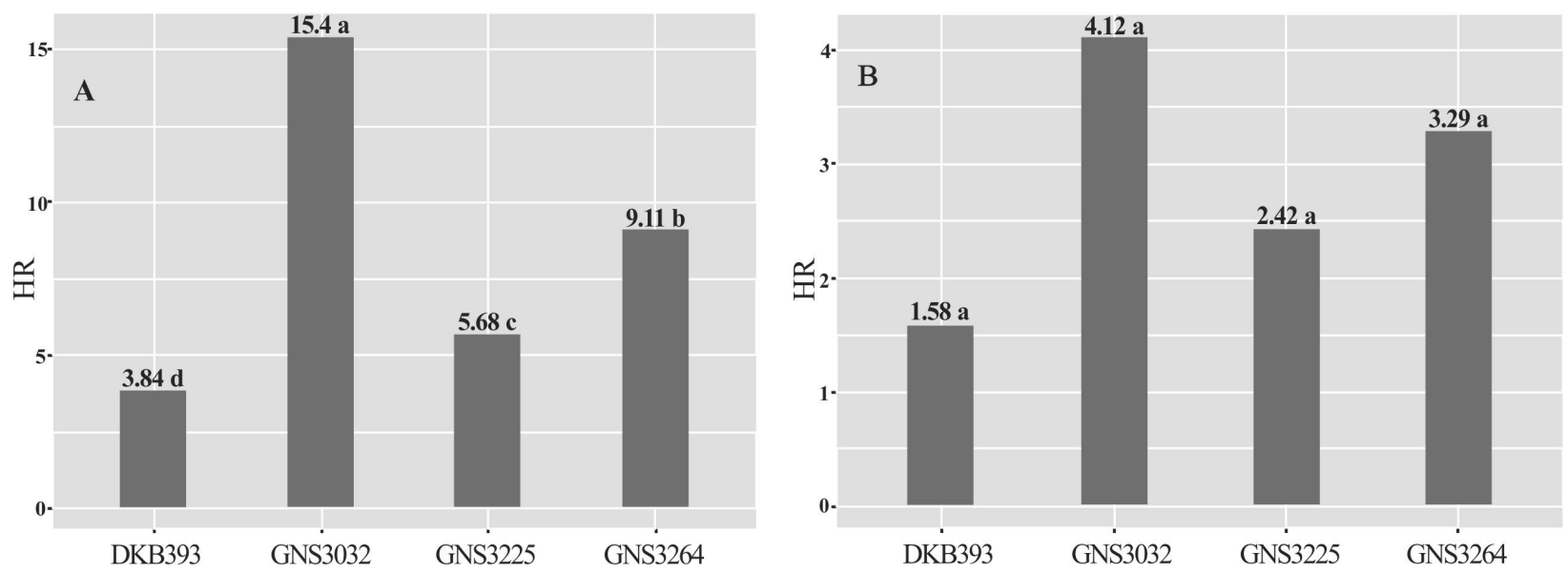

Figure 1: Mean percentages of haploid induction using the R1-Navajo marker (A) and haploid identification by flow cytometry (B). Mean percentages followed by the same letter belong to the same cluster. The values are based on the Mahalanobis distance with a cutoff of $5 \%$ probability. 


\section{Chromosome duplication of haploid lines}

First, it is necessary to emphasize that these analyses were conducted considering the number total of plants that survived the duplication stage and were analyzed by flow cytometry. The total number of plants that were subjected to the duplication protocols was not considered. In other words, the duplication analyses were conducted on a total number of seeds that was smaller than the total number of plants that were initially included in the study because various seedlings did not survive the colchicine treatment.

Thus, in the deviance analysis of the total number of duplicated plants, the protocols differed significantly between each other, as well as between the generations. The adjusted averages obtained by the deviance analysis of the chromosome duplication rate were $51.32 \%$ for the F1 generation and $65.67 \%$ for the $\mathrm{F} 2$ generation (Figure $2 \mathrm{~A}$ ). In the chromosome duplication protocol analyses, the highest rate of duplicated plants was obtained using Protocol 2 (69.33\%), whereas for Protocol 1, the rate was 51.32\% (Figure 2A). The hybrids did not differ significantly between each other regarding the duplicated plant rate.

Dang et al. (2012) observed rates of duplicated plants ranging from $28 \%$ to $54 \%$. Battistelli et al. (2013), in turn, obtained a higher percentage of duplicated plants, ranging from $59.1 \%$ to $80 \%$, whereas the percentages of plants duplicated by Choe et al. (2012) varied from 5\% to $57.1 \%$ in the evaluated hybrids.

The protocols used allow for some comparisons due to their divergent nature. Protocol 1 has a more practical methodology and is similar to that of Deimling, Rober and
Geiger (1997), differing only in the colchicine concentration. Protocol 2, in turn, has a more laborious methodology because seven or more days are necessary for the plant to grow sufficiently for its roots to be subjected to the duplication solution. Moreover, after reaching the ideal size, the plants need to be removed from the trays and washed with water to remove the sand and vermiculite that adhere to the roots. This stage is laborious and requires caution to avoid the destruction of the roots before the duplication stage.

The protocols used were efficient for the duplication of the plants. However, one of the objectives in this study was to obtain duplicated haploids and, thus, obtain doubled haploid lines. Therefore, statistical analyses were conducted in haploid plants that were duplicated to evaluate the efficiency of the two chromosome duplication methodologies. In the analysis of the duplicated haploid number, within the total number of haploids identified by flow cytometry, there were significant differences in the protocols and also in the generations. The adjusted averages obtained by the deviance analysis of the doubled haploid rate using the total number of haploids identified by flow cytometry were $50.96 \%$ in generation F1 and $64.61 \%$ in generation F2 (Figure 2B).

Protocol 2 was more efficient than Protocol 1 in this analysis. For the haploid duplication rate, Protocol 2 presented an average of $65.94 \%$, whereas Protocol 1 presented an average of $50.97 \%$ (Figure 2B). This finding indicates that despite having a more laborious methodology, Protocol 2 is more efficient for haploid duplication and attainment of doubled haploid lines. The hybrids used did not present significant differences regarding haploid duplication.
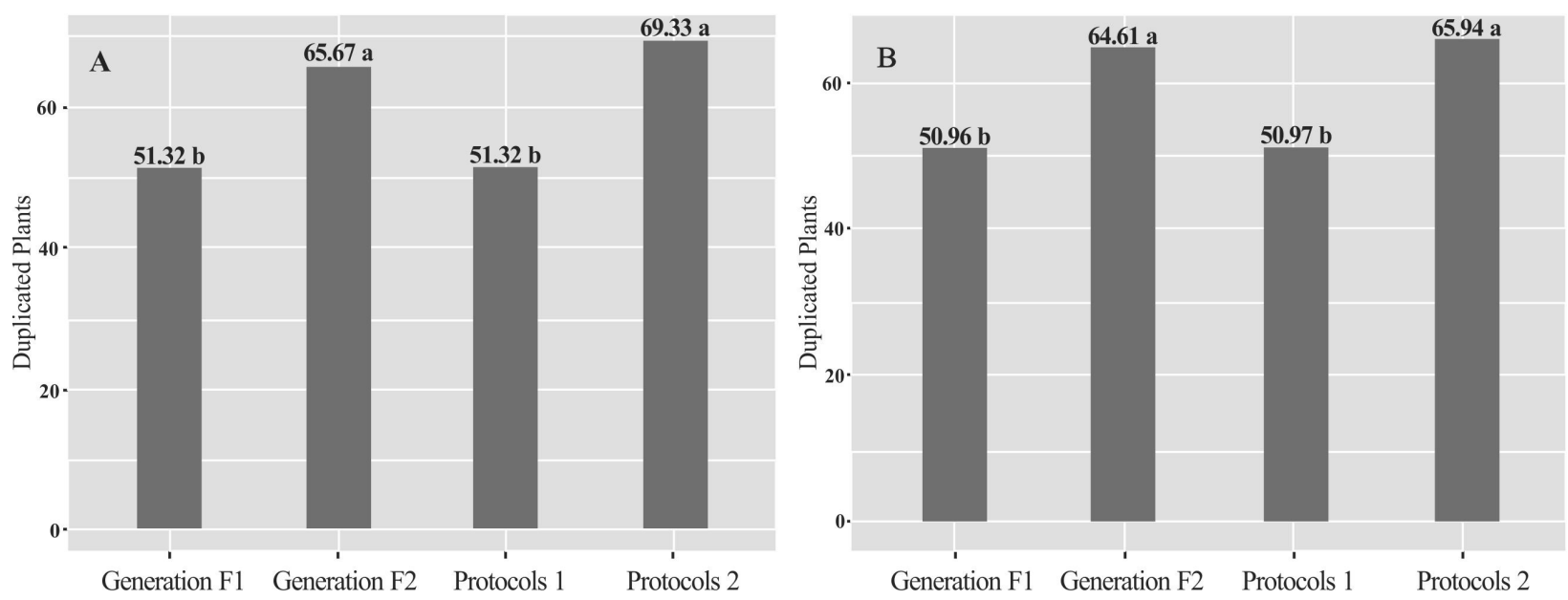

Figure 2: Mean percentages of the duplicated plants total (A) and duplicated haploids (B) considering generation F1 and F2 and protocols 1 and 2. Mean percentages followed by the same letter belong to the same cluster. The values are based on the Mahalanobis distance with a cutoff of $5 \%$ probability. 
It is important to emphasize that the cytometry results indicated the success of the chromosome duplication in the somatic cells of the plant (leaf), which does not guarantee that it is fertile and will produce seeds. The fertility of the tassel can be estimated using to the percentage of plants that produce pollen and are selffertilizing, which can be used to estimate the quantity of seeds harvested in duplicated haploid plants.

\section{Percentages of self-fertilized duplicated plants}

Companies seek to improve the attainment of doubled haploid seeds in their programs. Thus, the quantities of seeds harvested in each protocol and the number of doubled haploid seeds were determined.

Using the deviance analysis, we observed significant differences regarding the total number of duplicated plants that were self-fertilized for hybrids and the protocols.

For Protocol 2, an average of $65.19 \%$ of selffertilized plants was observed, whereas in Protocol 1, the average was $30.89 \%$. It was possible to verify that the efficiency of the duplication goes beyond the response of the hybrids to the colchicine, which was verified by the flow cytometry analysis. For Protocol 1, with average of $51.32 \%$ of duplicated plants (Figure 2A) determined by flow cytometry, a low average percentage of self-fertilized plants was found in the field (30.89\%). For Protocol 2, high average percentages of duplicated (69.33\%) (Figure 2A) and self-fertilized (65.19\%) plants was observed. As observed by Battistelli et al. (2013), it is important to emphasize that the results of chromosome duplication by the flow cytometry technique are evaluated only in the somatic cells of the leaves. In the field, a lower vigor and delay in the development of the duplicated haploid plants was observed compared to plants that did not respond to the colchicine.

For the deviance analysis, significant differences were observed for the hybrids used. However, in the grouping based on the Mahalanobis distance, the hybrids did not differ in the averages. Despite that, there was a considerable difference between the hybrids, with averages of $16.06 \%$ for the GNS 3264 hybrid, $23.04 \%$ for the GNS 3264 hybrid, $23.04 \%$ for the DKB 393 hybrid, $30.89 \%$ for the GNS 3032 hybrid, and $32.16 \%$ for the GNS 3225 hybrid.

These differing values, even for plants that belong to the same group based on the Mahalanobis distance, presented practical differences when the field experiment was conducted. GNS 3264 hybrid plants, for example, showed less vigor and development, as well as a delay in the formation of the tassel and liberation of the style and stigma, compared to the other hybrids.

The analyses by flow cytometry allowed the tracking of duplicated haploid plants in the field, and thus, it was possible to analyze which plants had fertile tassels and were self-fertilized. In the deviance analyses, significant differences between the generations of hybrids were observed. The adjusted averages obtained by the deviance analysis of the self-fertilized double-haploid rate were of $16.04 \%$ in generation $\mathrm{F} 1$ and $9.72 \%$ in generation $\mathrm{F} 2$.

\section{Quantities of seeds obtained by duplicated plants}

The quantities of ears harvested in this experiment are shown in Table 2. It was observed that more ears were harvested using Protocol 2 than Protocol 1. These data were expected because Protocol 2 was superior to Protocol 1 in the statistical analyses of duplicated plant self-fertilization.

It is interesting to note that doubled haploid technology, although advantageous, offers a much smaller final balance of harvested seeds than the number of seeds used at the beginning of this study. From the crosses of the four hybrids with the haploid inducer line KEMS, 15314 seeds were harvested, from which only 1086 were selected by the R1-Navajo marker. From that total of selected seeds that were duplicated, only 537 survived in the field, and at the final stage, 82 ears were harvested.

Table 2: Quantities of ears harvested in the field and ears of doubled haploid plants after the self-fertilization of duplicated plants.

\begin{tabular}{ccccc}
\hline \multirow{2}{*}{ Hybrids } & \multicolumn{2}{c}{ Quantity of harvested ears } & \multicolumn{2}{c}{ Quantity of doubled haploid ears } \\
\cline { 2 - 5 } & Protocol 1 & Protocol 2 & Protocol 1 & Protocol 2 \\
\hline GNS 3225 & 4 & 21 & 1 & 6 \\
GNS 3032 & 4 & 14 & 2 & 5 \\
GNS 3264 & 3 & 18 & 1 & 2 \\
DKB 393 & 7 & 11 & 6 & 2 \\
Total & 18 & 64 & 10 & 15 \\
\hline
\end{tabular}

Ciênc. Agrotec., Lavras, v. 39, n. 5, p. 435-442, set./out., 2015 
The quantities of harvested ears presented in Table 2 originate from duplicated plants of varied ploidies. Thus, as the main objective of the technology is to obtain doubled haploid seeds, the number of ears of doubled haploid plants harvested was analyzed. From the total of 82 harvested ears, 25 were from doubled haploid lines (Table 2). Protocol 2, once again, was superior to Protocol 1 in this analysis, presenting a higher number of harvested doubled haploid ears. The hybrids varied in the number of harvested ears.

\section{CONCLUSIONS}

The hybrid type influenced the HIR. However, the hybrid type did not influence in the rate of chromosome duplication of the tested protocols.

The inducer line KEMS is effective in inducing haploids in a tropical climate and can be used as an inducer line in tropical maize breeding programs.

Other markers, in addition to the R1-Navajo system, should be used in the selection of haploid seeds.

Protocol 2 was more efficient for the chromosome duplication of haploids regarding the percentage of selffertilized plants after duplication and for the attainment of doubled haploid lines.

\section{ACKNOWLEDGMENTS}

This research was supported by Conselho Nacional de Desenvolvimento Científico e Tecnológico (CNPq) and Fundação de Amparo à Pesquisa do Estado de Minas Gerais (FAPEMIG).

\section{REFERENCES}

BATES, D.; MAECHLER, M.; BOLKER, B. Lme4: linear mixed-effects models using S4 classes. Version 0.999375-42. Available in: http:// CRAN.R-project.org/ package=lme4. Access in: oct. 20, 2014.

BATTISTELLI, G.M. et al. Production and identification of doubled haploids in tropical maize. Genetics and Molecular Research. 2(4):4230-4242, 2013.

BELICUAS, P. R. et al. Androgenetic haploids and SSR markers as tools for the development of tropical maize hybrids. Euphytica. 156 (1/2):95-102, 2007.

CASTILLO, A. M. et al. Chromosome duplication in monocots. In: TOURAEV, A.; FORSTER, B. P.; JAIN, S. M. (Ed.). Advances in haploid production in higher plants. New York: Springer Science, 2009. p.329-338.
CHASE, S. S.; NANDA, D. K. Comparison of variability in inbred lines and monoploid-derived lines of maize (Zea mays L.). Crop Science. 5(4):275-276, 1965.

CHOE, E. H. et al. Improving in vivo maize doubled haploid production efficiency through early detection of false positives. Plant Breeding. 131(3):399-401, 2012.

COUTO, E. G. O. et al. Verification and characterization of chromosome duplication in haploid maize. Genetics and Molecular Research. 14(2):6999-7007, 2015.

DANG, N. C. et al. Inducer line generated double haploid seeds for combined waxy and opaque 2 grain quality in subtropical maize (Zea mays. L.). Euphytica. 183(2):153-160, 2012.

DEIMLING, S.; ROBER, F.; GEIGER, H. H. Methodik und genetik der in-vivo-Haploideninduktion bei mais. Vorträge für Pflanzenzüchtung. 38:203-224, 1997.

DOLEZEL, J. Application of flow cytometry for the study of plants genomes. Journal of Applied Genetics. 38(3):285-302, 1997.

EDER, J.; CHALYK, S. In vivo haploid induction in maize. Theoretical and Applied Genetics.104(4):703-708, 2002.

GEIGER, H. H.; GORDILLO, G. A. Doubled haploids in hybrid maize breeding. Maydica. 54(4):485-499, 2009.

HÄNTZSCHEL, K.R.; WEBER, G. Blockage of mitosis in maize root tips using colchicine-alternatives. Protoplasma. 241(1-4):99-104, 2010.

KEBEDE, A. Z. et al. Effect of source germplasm and season on the in vivo haploid induction rate in tropical maize. Euphytica. 180:219-226, 2011.

LI, H. et al. Doubled haploids versus conventional breeding in CIMMYT wheat breeding programs. Crop Science. 53(1):74- 83, 2013.

MELCHINGER, A.E. et al. In vivo haploid induction in maize: Identification of haploid seeds by their oil content. Crop Science. 54(4):1497-1504, 2014. 
NUNES, J.A.R.; MORAIS, A.R.; BUENO FILHO, J.S.S. Modelagem da superdispersão em dados binomiais por um modelo linear generalizado misto. Revista de Matemática e Estatística. 22(1):55-70, 2004.

PATTERSON, H.D.; THOMPSON R. Recovery of inter-block information when block sizes are unequal. Biometrika. 58(3):545-554, 1971.

PRASANNA, B.M.; CHAIKAM, V.; MAHUKU, G. (Ed.). Doubled haploid technology in maize breeding: theory and practice. Mexico: CIMMYT, 2012.

PRIGGE, V. et al. Development of in vivo haploid inducers for tropical maize breeding programs.

Euphytica. 185(2):481-490, 2012.

. New insights into the genetics of in vivo induction of maternal haploids, the backbone of doubled haploid technology in maize. Genetics. 190(2):781-793, 2012.

. Doubled haploids in tropical maize:

effects of inducers and source germplasm on in vivo haploid induction rates. Crop Science. 51(1):1498-1506, 2011.
RÖBER, F. K.; GORDILLO, G. A.; GEIGER, H. H. In vivo haploid induction in maize-performance of new inducers and significance of doubled haploid lines in hybrid breeding. Maydica. 50(3/4):275-283, 2005.

ROTARENCO, V. A.; DICU, G.; SARMANIUC, $\mathrm{M}$. Induction of maternal haploids in maize. Maize

Genetics Cooperation Newsletter. 83, 2009.

ROTARENCO, V. A. et al. New inducers of maternal haploids in maize. Maize Genetics Cooperation Newsletter. 84, 2010.

SHATSKAYA, O. A. et al. Mass induction of maternal haploids in corn. Maize Genetics Cooperation Newsletter. 68:51, 1994.

WU, P. et al. Mapping of maternal QTLs for in vivo haploid induction rate in maize (Zea mays L.).

Euphytica. 196(2):413-421, 2014.

WU, P. et al. Early spontaneous diploidization of maternal maize haploids generated by in vivo haploid induction. Euphytica. 200(1):127-138, 2014. 